\title{
Multiple-input Single-output Voltage-mode Universal Biquadratic Filter Uisng URC and CCCDBA
}

\author{
Sorapong Wachirarattanapornkul \\ Faculty of Engineering, \\ King Mongkut's Institute of Technology Ladkrabang \\ Bangkok, Thailand \\ e-mail: kssorapo@kmitl.ac.th
}

\begin{abstract}
In this paper, a new three-input single-output voltage-mode universal biquadratic filter using two uniformly distributed RC (URC) and current-controlled current differencing buffered amplifier (CCCDBA) are presented. The proposed circuit can realize to low-pass (LPF), high-pass (HPF), band-pass (BPF) and band-stop (BSF) biquadratic functions and provided independent electronic tuning of the natural angular frequency, the quality of the CCCDBA. The proposed circuits have active and passive sensitivities are low and suitability to integrated circuit implementation. The characteristic of the proposed universal biquadratic filter circuit are simulation using PSPICE that confirm the theoretical prediction are also given and discussed
\end{abstract}

Keywordst-voltage-mode circuit, biquad filter, URC and CCCDBA

\section{INTRODUCTION}

Universal biquadratic filters are a useful class of currentmode as well as voltage-mode filter, since they can realize different filtering functions with the same topology depending on the port used. Recently, the application of new active building blocks such as operational transconductance amplifiers (OTAs)[1]-[2], current feedback amplifiers(CFAs) [3]-[4], second generation current conveyor [5]-[6] and current differencing buffered amplifier (CDBA) [7]-[8] have been received a wide attention due to their lager dynamic and wider bandwidth. The design techniques of high performance active building blocks such devices mentioned above have also considerable interest. A current-controlled current differencing buffered amplifier (CCCDBA) [9] is one of active building blocks an important of the wellknown current conveyor. And the characteristics of URC element have several advantages over lump RC network. The structure of distributed RC elements in thin-film technology is built using smaller high frequency and the structure of the general URC [10]-[12] consists of layers of conductors, resistive layer and dielectrics can be sandwiched together in many permutations.

This paper presents the voltage-mode biquadratic filter using two CCCDBA and two URC, the filter can realize the low pass, high pass and band pass filter transfer function by connecting the terminal of $V_{a}, V_{b}$ and $V_{c}$ to the ground or to the input voltage $V_{i n}$. The characteristics parameters $\omega_{0}$ and
$Q_{c}$ can also be set orthogonally by adjusting the bias current of the CCCDBA. Some examples are given together with simulation results by PSPICE and MATLAB

\section{CIRCUIT DESCRIPTION}

\section{A. Uniformly Distributed RC (URC)}

The uniformly distributed RC element (URC) have several advantage over lumped RC network to active filter. The structure of distributed RC [10], elements in thin-film or VLSI technology is built using smaller substrate area, less isolation and parasitic problems at high frequency. Distributed RC elements many form structures [11]. The structure and circuit symbol of URC as shown in Fig.1.

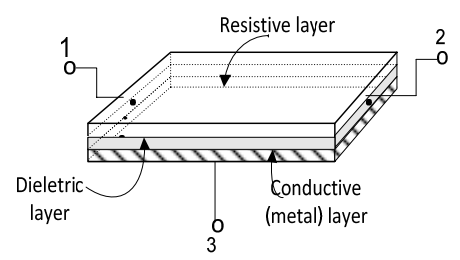

(a)

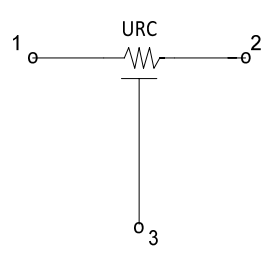

(b)
Figure 1 URC (a) A uniformly distribute RC section (b) Symbolic of URC

The admittance parameters [Yij] of URC Fig.1 is given as follows:

$$
\left[\begin{array}{l}
I_{1} \\
I_{2} \\
I_{3}
\end{array}\right]=X\left[\begin{array}{ccc}
Y & -1 & -(Y-1) \\
-1 & Y & -(Y-1) \\
-(Y-1) & -(Y-1) & 2(Y-1)
\end{array}\right]\left[\begin{array}{c}
V_{1} \\
V_{2} \\
V_{3}
\end{array}\right]
$$

Where $X=P / R \sinh P, Y=\cosh P$ and $P=\sqrt{S R C}$

Where $R$ and $C$ are the value of the total resistance and capacitance of the URC respectively and $S$ is the complex frequency variable. 


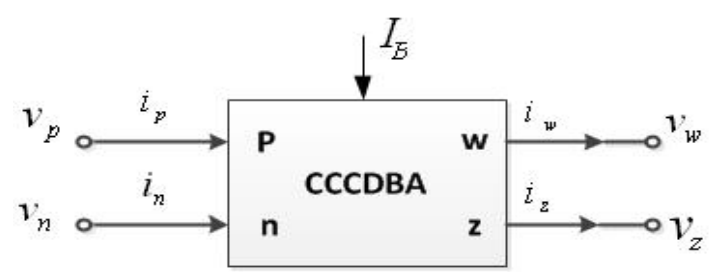

(a)

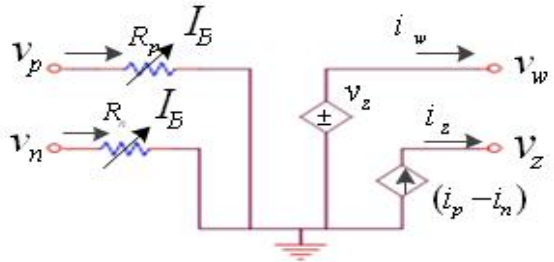

(b)

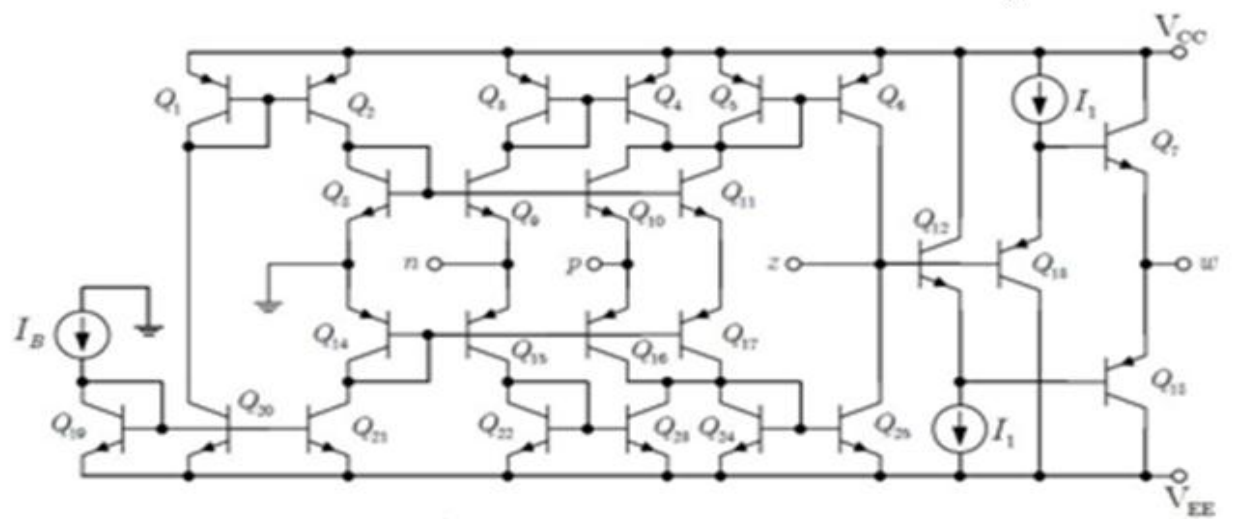

(c)

Figure 2 CCCDBA a) circuit symbol (b) equivalent circuit (c) bipolar realization of the CCCDBA[9]

The circuit representation and equivalent of the CCCDBA are shown in Fig. 2, where $p$ and $n$ are input and $w$ and $z$ are output terminals. The characteristic of this device can be defined by the flowing matrix equation[9].

$$
\left[\begin{array}{l}
v_{p} \\
v_{n} \\
i_{z} \\
v_{w}
\end{array}\right]=\left[\begin{array}{cccc}
0 & 0 & R_{p} & 0 \\
0 & 0 & 0 & R_{n} \\
0 & 0 & 1 & -1 \\
1 & 0 & 0 & 0
\end{array}\right]\left[\begin{array}{l}
v_{z} \\
i_{w} \\
i_{p} \\
i_{n}
\end{array}\right]
$$

Where $R_{p}$ and $R_{n}$ are the parasitic resistances at the terminals $p$ and $n$ of the CCCDBA, respectively. As an example, a possible bipolar realization of the CCCDBA is shown in Fig.2(c) [9]. In this case, the resistances $R_{p}$ and $R_{n}$ can be given by;

$$
R_{p} \cong R_{n} \cong \frac{V_{T}}{2 I_{B}}
$$

Where $V_{T}$ is the thermal voltage that is equal to $26 \mathrm{mV}$ at room temperature. Form Eq.(3) shows that it is possible to tune the values of $R_{p}$ and $R_{n}$ by means of an external dc bias current $I_{B}$

\section{THE PROPOSED CIRCUIT}

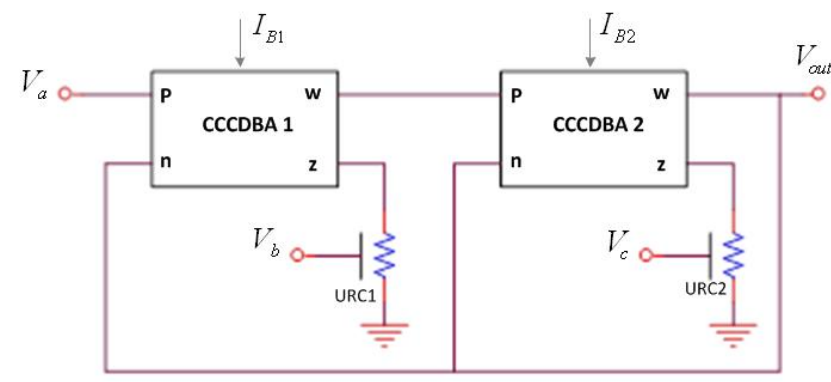

Figure 3 The proposed circuit

Fig. 3 shows the proposed of multiple-input singleoutput voltage-mode universal biquadratic filter circuit with consists of only two CCCDBAs and two URCs. The universal biquad filter can be used a lowpass, highpass bandpass and banstop second-order filter section. Routine circuit analysis using equation (4) yields the following single output voltage.

$$
V_{\text {out }}=\frac{\left(1 / R_{p 1} R_{p 2}\right) V_{a}+\left(X_{1}\left(2 Y_{1}-1\right) / R_{p 2}\right) V_{b}+\left[X_{1} Y_{1} X_{2}\left(2 Y_{2}-1\right)\right] V_{c}}{\left(1 / R_{n 1} R_{p 2}\right)+\left({ }^{X_{1} Y_{1} / R_{n 2}}\right)+X_{1} Y_{1} X_{2} Y_{2}}(4)
$$

Where $X_{1}=\frac{P_{1}}{R_{1} \sinh P_{1}}, Y_{1}=\cosh P_{1}, X_{2}=\frac{P_{2}}{R_{2} \sinh P_{2}}$, 


$$
Y_{2}=\cosh P_{2}, P_{1}=\sqrt{S R_{1} C_{1}}, P_{1}=\sqrt{S R_{2} C_{2}},
$$

$R_{n i}=R_{p i}=V_{T} / 2 I_{B i}$ for $i=1,2$. In this case, $R_{n i}$ and $R_{p i}$ denote the parasitic resistance $R_{p}$ and $R_{n}$ of the $i$-th CCCDBA, respectively.

From equation (4), it can be observed that the configuration can be used as a voltage-mode three input single input universal filter as follows.

1) The low pass filter function can be realized, if $V_{a}=V_{\text {in }}$ (an input voltage signal) and $V_{b}=V_{c}=0$ (grounded) as follows;

$$
\frac{V_{\text {out }}}{V_{a}}=\frac{\left(1 / R_{p 1} R_{p 2}\right)}{\left(1 / R_{n 1} R_{p 2}\right)+\left({ }^{X_{1} Y_{1} / R_{n 2}}\right)+X_{1} Y_{1} X_{2} Y_{2}}
$$

2) The band pass filter function can be realized, if $V_{b}=V_{\text {in }}$ and $V_{a}=V_{c}=0$ as follows;

$$
\frac{V_{\text {out }}}{V_{b}}=\frac{\left[X_{1}\left(2 Y_{1}-1\right) / R_{p 2}\right]}{\left(1 / R_{n 1} R_{p 2}\right)+\left(X_{1} Y_{1} / R_{n 2}\right)+X_{1} Y_{1} X_{2} Y_{2}}
$$

3) The high pass filter function can be realized, if $V_{c}=V_{\text {in }}$ and $V_{a}=V_{b}=0$ as follows;

$$
\frac{V_{\text {out }}}{V_{c}}=\frac{X_{1} Y_{1} X_{2}\left(2 Y_{2}-1\right)}{\left(1 / R_{n 1} R_{p 2}\right)+\left({ }^{\left.X_{1} Y_{1} / R_{n 2}\right)+X_{1} Y_{1} X_{2} Y_{2}}\right.}
$$

4) The band stop filter function can be realized, if $V_{a}=V_{c}=V_{\text {in }}$ and $V_{b}=0$ as follows;

$$
\frac{V_{\text {out }}}{V_{\text {in }}}=\frac{\left(1 / R_{p 1} R_{p 2}\right)+\left[X_{1} Y_{1} X_{2}\left(2 Y_{2}-1\right)\right]}{\left(1 / R_{n 1} R_{p 2}\right)+\left(X_{1} Y_{1} / R_{n 2}\right)+X_{1} Y_{1} X_{2} Y_{2}}
$$

Therefore, the proposed filter is capable of realizing four the standard biquadratic filter functions, while keeping a minimum number of the CCCDBA and URC components. The natural angular frequency $\left(\omega_{o}\right)$, the $Q$-Factor $Q_{c}$ and the bandwidth $(B W)$ of the proposed filter can be expressed as.

$$
\begin{gathered}
\omega_{o}=\frac{1}{\sqrt{R_{p} R_{n} R_{1} R_{2} C_{1} C_{2}}} \\
B W=\frac{1}{R_{n 1} R_{1} C_{1}} \\
Q_{c}=\sqrt{\frac{R_{n 1} R_{1} c_{1}}{R_{p 2} R_{2} c_{2}}}
\end{gathered}
$$

\section{SENSITIVITY}

The sensitivity $S_{X_{i}}^{T(P)}$ is defined as the ratio of the normalized incremental change of the transfer function $T(P)$ due to the normalized change of circuit parameter $X_{i}$ as follow:

$$
S_{X_{i}}^{T(P)}=\frac{d T(P)}{d x_{i}} \cdot \frac{x_{i}}{T(P)}
$$

As form equation (13)-(17) the active and passive sensitivities of the proposed circuit can be found such as:

$$
\begin{aligned}
& S_{R_{p, n}}^{\omega}=S_{c_{1,2}}^{\omega}=S_{R_{1,2}}^{\omega}=\frac{1}{2} \\
& S_{R_{n 1}}^{B W}=S_{c_{1}}^{B W}=S_{R_{1}}^{B W}=-\frac{1}{2} \\
& S_{R_{p 2}}^{B W}=S_{c_{2}}^{B W}=S_{R_{2}}^{B W}=0 \\
& S_{R_{n 1}}^{Q}=S_{c_{1}}^{Q}=S_{R_{1}}^{Q}=\frac{1}{2} \\
& S_{R_{p 2}}^{Q}=S_{c_{2}}^{Q}=S_{R_{2}}^{Q}=-\frac{1}{2}
\end{aligned}
$$

Note that all the sensitivity values are within unity in magnitude, which represent a low value. Hence, the proposed exhibits good sensitivity performance

\section{Simulation Results}

In order to verify the results of the theoretical analysis given above, the proposed filter has been simulation with PSPICE and MATLAB program. For CCCDBAs, the bipolar implementation with supply voltage of $\pm 3 \mathrm{~V}$ and all the bias current $I_{B}$ were set be constant at $50 \mu \mathrm{A}$ and the $\mathrm{URC}$ is approximated by the ladder lumped RC elements of 10 sections with selects the URC element value as follow;

$$
\begin{gathered}
R_{1}=100 \mathrm{k} \Omega, C_{1}=100 \mathrm{nF}, \\
R_{2}=20 \mathrm{k} \Omega, C_{2}=320 \mathrm{nF},
\end{gathered}
$$

As an example to obtain a universal filter with a natural angular frequency of $f_{0}=1.023 \mathrm{MHz}$ and a quality factor of $Q_{C}=1$. The resulting frequency response of the lowpass, highpass and bandpass filter functions obtained from the simulations are shown in Fig.4. 


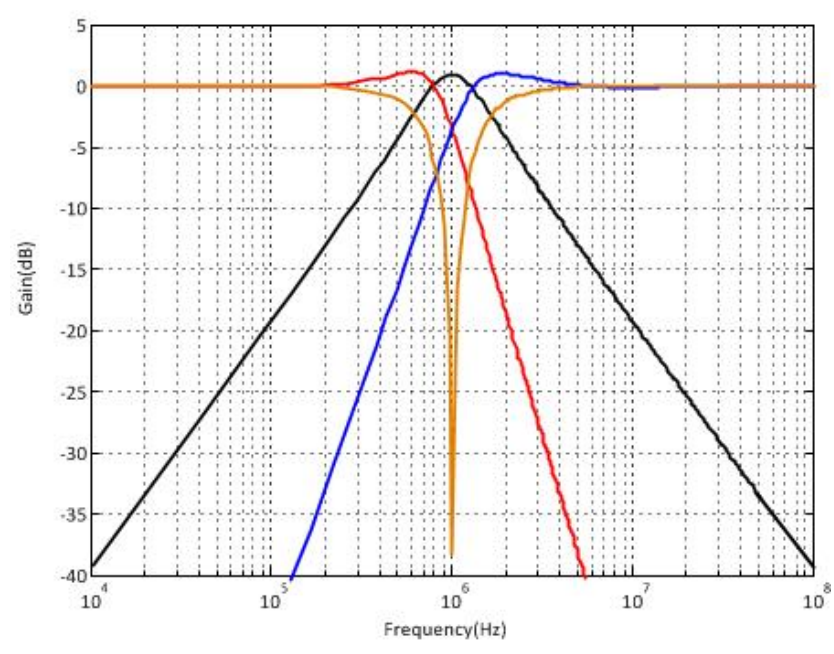

Figure 4 MATLAB simulation results for lowpass, highpass, bandpass and bandstop response of the propose filter

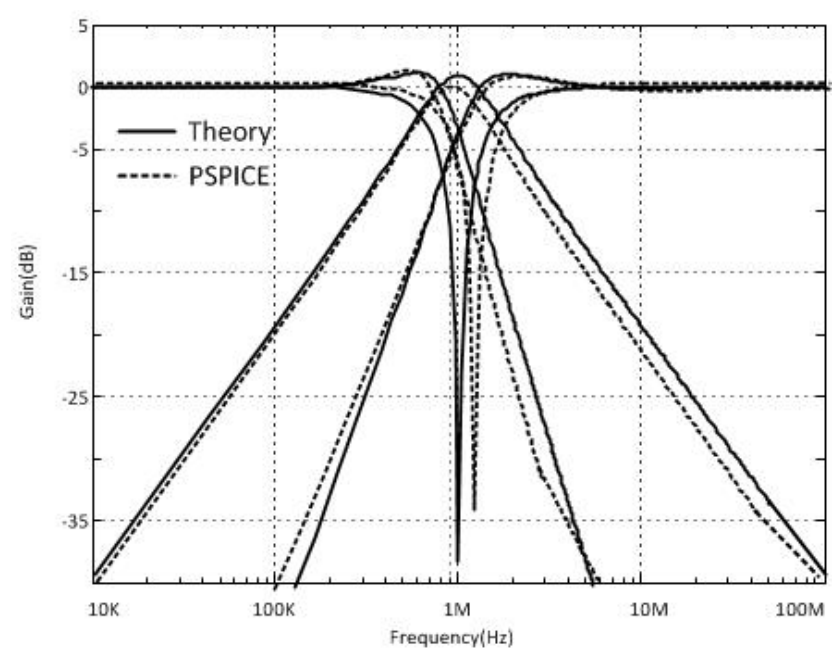

Figure 5 Frequency response of proposed circuit with comparision theory and PSPICE

The power consumption for each case is approximately $28.2 \mathrm{~mW}$. All the simulation results are found to be in good agreement with the theoretical values .

\section{CONCLUSION}

The multiple-input single-output voltage-mode universal biquadratic filter has been described. The circuit use two CCCDBA and two URC, which are minimum component count circuit and hence the advantages a low-cost solution, chip area, power dissipation and noise. The proposed filter offers lowpass, highpass, bandpass and bandstop biquadratic characteristics. The filter also provides the attractive feature of independent electronic tuning of $\omega_{o}, Q_{c}$ and $B W$ through an external bias current, no component matching requirement, as well as low active and passive sensitivities. MATLAB and PSPICE simulation proved that all the deviations from the theory can be reduced by properly adjusting the external bias current.

\section{REFERENCES}

[1] CM. Chang, "New Multifunction OTA-C Biquad," IEEE Trans Circuit System II: Analog Digit Signal Process 1999, 46:820-4.

[2] CM. Chang and SK. Pai, "Universal Current-Mode OTA-C Biquad with minimum components," IEEE Trans Circuit System I: Fundamental Theory Application 2000, 47:1235-8

[3] S. I. Liu, "Universal filter using two current feedback amplifiers," Electron.Lett., vol. 31, pp. 629-630, 1995.

[4] J. W. Horng, "New configuration for realizing universal voltage mode filter mode filter using CFAs," IEEE Trans. Instrum.Meas., vol. 49, pp. $1043-1045,2000$

[5] M. Higashimura, "Realization of voltage-mode biquad using CCII+," Electron.Lett., vol. 27, pp. 1345-1346, 1991.

[6] W. Tangsrirat and W. Surakampontom, "Realization of multipleoutput biquadratic filter using current differencing buffered amplifiers," Int.J.Electron, vol. 92, pp. 313-325, 2005.

[7] W. Tangsrirat and W. Surakampontom, "High output impedance current-mode universal filter employing dual-output current controlled conveyors and grounded capacitors," Int.J.Electron, vol. 61, pp. 127-131, 2007

[8] A. U. Keskin, "Multi-function biquad using single CDBA," Electrical Engineering, vol. 80, pp. 353-356, 2006.

[9] E. Yuce, S. Minaei and M. Metin, "Electronically tunable currentmode second-order universal filter using minimum elements," Electron, Lett., vol. 41, pp. 453, 2005

[10] M.S. Ghausi and J.J.Kelly, "Introduction to Distributed Parameter Networks with Application to Integrated Circuits," Holt, Rinehart and Winston INC., pp.136-141.

[11] M. Teramoto, S. Sudo, "Active distributed RC antialiasing/smoothing filters," IEEE- ISCAS, 1991.

[12] S.Wachirarattanapornkul, "On design of active notch tunable filter using multilayer uniformly distributed RC line," 9th International Symposium on Communications and Information Technology, 2009. (ISCIT 2009), pp. 605-608, 2009. 